\title{
ORGANIZAÇÃO SOCIAL DE EDUCAÇÃO E SEU FINANCIAMENTO: A NOVA PANACEIA PARA EDUCAÇÃO DE GOIÁS?
}

\author{
Fábio Araujo de Souza ${ }^{1}$ \\ Maria Marta Lopes Flores ${ }^{2}$
}

\section{Resumo}

$\mathrm{O}$ artigo apresenta os resultados da pesquisa que analisou o processo de implantação da gestão compartilhada, em Goiás, entre a Secretaria de Estado de Educação, Cultura e Esporte (Seduce) e a Organização Social de Educação (OSE) selecionada pela secretaria. O objeto desta pesquisa se refere aos aspectos relacionados à transferência, acompanhamento e controle social dos recursos da manutenção e desenvolvimento do ensino e da educação para a OSE. Esta pesquisa é qualitativa e quantitativa, de natureza exploratória para a investigação do tema e com isso compreende o problema e os fatores subjacentes ao objeto pesquisado. Para analisar a transferência dos recursos da educação para a OSE que venha a gerenciar as unidades escolares de Goiás, foi realizado um levantamento no orçamento do estado para 2016 e 2017, nas legislações, nos Chamamentos Públicos e nos demais documentos que envolvem o processo de implantação da gestão compartilhada. Foi realizado, também, um levantamento bibliográfico sobre Organizações Sociais (OSs) em notícias de sites oficiais do governo e de entidades que discutem o tema, bem como, em artigos científicos e demais fontes pertinentes, a fim de se analisar, sob a perspectiva crítica, o processo de implantação das OSE na rede estadual. Como resultado foi possível constatar que há muitas incertezas e incoerências no processo de implantação da gestão compartilhada através da OSE na educação básica, especificamente, no que se refere ao seu financiamento.

Palavras-chave: Organização social. Gestão compartilhada. Financiamento da educação.

\section{SOCIAL ORGANIZATION OF EDUCATION AND ITS FUNDING: A NEW PANACEA FOR EDUCATION OF GOIÁS?}

\begin{abstract}
The article presents the results of the survey that analyzed the deployment process of shared management, in the state of Goiás, between the State Department of Education, Culture and Sport (Seduce), and the Social Organization of Education (OSE) selected by the secretary. The object of this research refers to aspects related to the transfer, monitoring and social control of the resources of the maintenance and development of education and education for the OSE. This research is qualitative and quantitative in nature) exploratory research of the theme and with this you understand the problem and the factors underlying the object of research. To analyze the transfer of education resources to the OSE that will
\end{abstract}


manage the schools of the state of Goiás was carried out a survey in the state budget for 2016 and 2017, in the laws, on the Grounds of Public and other documents that involve the deployment process of shared management. Was held, also, a bibliographical survey on Social Organizations (OSs), in news from official sites of the government and government entities that discuss the topic, as well as in scientific articles and other relevant sources, to analyze, under the critical perspective, the implementation process of the OSE in the state network. As a result it was possible to see that there are many uncertainties and inconsistencies in the process of implementing the shared management by the OSE in basic education, specifically, in what refers to its financing.

Keywords: Social organization. Shared management. The financing of education.

\section{LA ORGANIZACIÓN SOCIAL DE LA EDUCACIÓN Y SU FINANCIAMIENTO: LA NUEVA PANACEA PARA LA EDUCACIÓN DE GOIÁS?}

\section{Resumen}

El artículo presenta los resultados de una investigación que analizó el proceso de implementación de la gestión compartida, en Goiás, entre la Secretaría de Estado de Educación, Cultura y Deporte (Seduce) y la Organización Social de la Educación (OSE) seleccionada por la secretaría. El objeto de esta investigación se refiere a los aspectos relativos a la transferencia, seguimiento y control social de los recursos de mantenimiento y desarrollo de la enseñanza y de la educación para la OSE. Esta investigación es qualicuantitativa de naturaleza exploratoria para la investigación del tema y con esto comprende el problema y los factores subyacentes al objeto investigado. Para analizar la transferencia de los recursos de la educación para la OSE que venga a administrar las unidades escolares de Goiás, fue realizado un levantamiento en el presupuesto del estado para el año 2016 y 2017, en las legislaciones, los Gritos Públicos y en los demás documentos que implican el proceso de implementación de la gestión compartida. Se ha realizado un estudio bibliográfico sobre las Organizaciones Sociales (OSs), en las noticias de los sitios web oficiales del gobierno y de entidades que tratan sobre el tema, así como en artículos científicos y otras fuentes pertinentes, a fin de analizar, desde la perspectiva crítica, el proceso de implementación de las OSE en la red estatal. Como resultado, fue posible constatar que hay mucha incertidumbre y las incoherencias en el proceso de implementación de la gestión compartida a través de la OSE en la educación básica, específicamente, en lo que se refiere a su financiación.

Palavras clave: Organización social. Gestión compartida. Financiamiento de la educación. 


\section{INTRODUÇÃO}

O inovador projeto de gestão compartilhada entre uma Organização Social de Educação (OSE) e a Secretaria de Estado de Educação, Cultura e Esporte (Seduce) de Goiás tem causado muitos questionamentos com relação aos efeitos que esse modelo trará para a educação estadual, sobretudo para os professores da educação básica da rede estadual. Um clima de incerteza, insegurança e dúvida tem perturbado os envolvidos direta e indiretamente com a educação estadual.

O presente artigo apresenta os resultados da pesquisa que analisou o processo de implantação da gestão compartilhada em unidades escolares da Educação Básica da rede estadual de educação de Goiás, principalmente, no que se refere aos recursos públicos para educação que envolvem esse projeto. Esta pesquisa é qualitativa e quantitativa de natureza exploratória para a investigação do tema e com isso compreende o problema e os fatores subjacentes ao objeto pesquisado. $\mathrm{O}$ estudo exploratório conduz a uma aproximação à realidade estudada e tem um caráter não estruturado; a investigação qualitativa permite com mais facilidade, e sem grandes filtros, captar uma massa muito ampla de dados e informações que servirão de base ao tema explorado.

Esta pesquisa está fundamentada na Teoria marxiana que se consolida na análise profunda do objeto ou fenômeno social revelando a sua essência e expondo criticamente a sua pseudoconcreticidade. (KOSIK, 1976). O método de Marx está dividido em dois momentos inseparáveis: a investigação (Forschungsmethode) e a exposição (Darstellungsmethode). A investigação, ou o método de investigação, é a apropriação analítica, reflexiva, em seus pormenores, do objeto pesquisado; e o método de exposição é a exposição crítica do objeto, com base nas suas contradições, ou seja, o objeto de investigação necessita de uma análise profunda e detalhada, para se entender o seu movimento interno e depois expor adequadamente sua lógica interna. (MARX; ENGELS, 1988).

Para analisar a transferência dos recursos da educação para a OSE que venha a gerenciar as unidades escolares de Goiás, foi realizado um levantamento no orçamento do estado para 2016 e 2017, nas legislações, nos Chamamentos Públicos e nos demais documentos que envolvem o processo de implantação da gestão compartilhada. Foi realizado, também, um levantamento bibliográfico sobre Organizações Sociais (OSs), em notícias de sites oficiais do governo e de entidades que discutem o tema, bem como em artigos científicos e demais fontes pertinentes.

Este artigo está dividido em quatro partes, em que a primeira aborda aspectos históricos da implementação das OSs no país; a segunda trata do processo de implantação das OSs na educação básica em Goiás; a terceira apresenta a análise dos Chamamentos Públicos, especificamente, sobre a questão do financiamento da gestão compartilhada; e a última parte traz os aspectos conclusivos da pesquisa. 


\section{ASPECTOS HISTÓRICOS DA IMPLEMENTAÇÃO DE UM NOVO MODELO GERENCIAL NO SETOR PÚBLICO BRASILEIRO}

Na intensa crise estrutural capitalista que assolou o desenvolvimento dos países da América Latina nas décadas de 1980 e 1990, sobretudo pelos vertiginosos empréstimos contraídos de bancos privados, o governo norte-americano aliado a órgãos econômicos internacionais, como o Banco Mundial, através do Consenso de Washington, lançou propostas neoliberais para a retomada do desenvolvimento econômico dos países latinos. Partia-se do pressuposto de que a crise que afetou os países da América Latina foi oriunda, principalmente pela falta de competência dos Estados para administrar, responsavelmente, os recursos de seus territórios. As propostas do Consenso de Washington abrangiam ações para manter a disciplina fiscal, a reforma tributária, a liberalização financeira, a desregulação, a privatização, o regime cambial, dentre outras.

Os efeitos dos princípios neoliberais implementados na política econômica do Brasil, mais intensamente na década de 1990, como a saída para a crise econômica, conduziu o país ao ideário de que o Estado só poderia superar seus graves entraves através da eficiência da gestão, da gerência pela busca por resultados. Assim sendo, as maneiras mais eficazes para isso seria através da privatização, ou seja, da venda de empresas públicas estatais para o setor privado; da terceirização, que é basicamente a gestão das empresas públicas pelo setor privado; ou através da gestão compartilhada que se baseia na contratação do Terceiro Setor para gerenciar junto com o Poder Público alguns serviços públicos.

Na década de 1990, no governo do Presidente Fernando Collor, o Brasil intensificou o processo de privatização da economia com o Programa Nacional de Desestatização (PND) instituído pela Lei n. 8.031, de 12 de abril de 1990; porém é mister ressaltar que esse processo tem suas origens no governo de João Figueiredo, quando, em 1981, é criada a Comissão Especial de Desestatização, responsável pela privatização de 20 empresas. Tal projeto tem continuidade durante o governo Sarney quando mais 18 empresas foram privatizadas, das quais 12 eram controladas pelo Banco Nacional de Desenvolvimento Econômico e Social (BNDES). (ALMEIDA, 2010).

A reforma gerencial do Estado brasileiro encontrou terreno fértil nos governos do Presidente Fernando Henrique Cardoso (1995-1998 e 1999-2002), em que o Plano Real e a estabilização da economia levaram à implementação de mudanças no campo políticoadministrativo e gerencial. Um Estado mais eficiente e menos burocrático era vislumbrado pelas reformas do Ministério da Administração Federal e Reforma do Estado (MARE), que tinha como ministro o advogado e economista Luiz Carlos Bresser-Pereira. A necessidade da reforma gerencial se fazia presente nos discursos governamentais, pois o Estado " $[$...] apresentava problemas de 'governança', considerando que a gestão era rígida e ineficiente, 
e isso impedia a implantação de políticas públicas mais flexíveis." (SOUZA; SILVA, 2008, p. 264).

Em 1995, Fernando Henrique Cardoso cria o Plano Diretor da Reforma do Aparelho do Estado (PDRAE) cuja ideia principal era possibilitar atividades não exclusivas do Estado, como gestão de museus, teatros, hospitais e de institutos científicos. Assim, o então ministro Bresser-Pereira dá início ao processo de reforma administrativa e gerencial da Administração Pública no país.

O governo buscou atrair entidades da sociedade civil organizada com o fim de formular parcerias na execução de programas sociais, numa conceituação de terceirização singular, porém não assumida de fato: no lugar de terceirização, adotou-se o neologismo publicização. Dessa forma, entidades da sociedade civil agiriam como parceiras do Estado, desde o planejamento até a execução de serviços.

Entre as soluções apontadas pelo PDRAE estava a atração de entidades da sociedade civil organizada com o fim de formular parcerias na execução de programas sociais mediante a publicização, ou seja, a descentralização para o setor público não estatal da execução de serviços que não envolvem, necessariamente, o exercício do poder de Estado, mas que devem ser subsidiados pelo Estado, como é o caso dos serviços de educação, saúde, cultura e pesquisa científica.

Segundo o ministro Bresser-Pereira (1997, p. 13):

O Projeto Organizações Sociais, no âmbito do Programa Nacional de Publicização (PNP), tem como objetivo permitir a publicização de atividades no setor de prestação de serviços não-exclusivos, baseado no pressuposto de que esses serviços ganharão em qualidade: serão otimizados mediante menor utilização de recursos, com ênfase nos resultados, de forma mais flexível e orientados para o cliente-cidadão mediante controle social.

Segundo Adrião e Peroni (2007) a transferência de políticas sociais para o denominado setor público não-estatal justificar-se-ia teórica e ideologicamente pela disseminação da chamada Terceira Via, pela atuação de seu operador nas práticas sociais o Terceiro Setor ou por sua variação institucionalizada, as Organizações Sociais. "Nesse caso, o Estado, mesmo se retirando da execução das políticas sociais, mantém-se como seu financiador ou co-financiador." (ADRIÃO; PERONI, 2007, p. 257).

A Lei federal n. 9.637, de 15 de maio de 1998, foi criada pelo ministro BresserPereira com os objetivos de dispor sobre a qualificação de entidades como Organizações Sociais; criar o Programa Nacional de Publicização (PNP), extinguindo o Laboratório Nacional de Luz Síncrotron e a Fundação Roquette Pinto; e absorver suas atividades por OSs.

Segundo a referida lei, as Organizações Sociais são qualificadas como pessoas jurídicas de direito privado, sem fins lucrativos, com atividades dirigidas ao ensino, à 
pesquisa científica, ao desenvolvimento tecnológico, à proteção e preservação do meio ambiente, à cultura e à saúde. Têm como conselho de administração, o órgão de deliberação institucional das OSs, um dos maiores mecanismos de controle disponibilizados tanto ao Poder Público quanto à sociedade, por meio das quotas de composição a eles destinadas. (PINTO, 2000).

Está previsto na lei supracitada que as OSs devem elaborar um contrato de gestão com o Poder Público com objetivo de formar parceria entre as partes para fomento e execução de atividades relacionadas à área pretendida. Esse documento deve discriminar as atribuições, responsabilidades e obrigações do Poder Público e da OS. Segundo Meira (2012, p. 98), nesse "[...] contrato incluem-se o tipo de atuação da entidade, as metas estabelecidas e os respectivos prazos, além dos objetivos e dos critérios predeterminados para a avaliação, baseados em conceitos quantitativos e qualitativos." No que se refere aos recursos orçamentários e bens públicos, a lei define que serão assegurados de acordo com o cronograma de desembolso previsto no contrato de gestão. A fiscalização da execução do contrato de gestão, segundo a lei, será realizada pelo órgão ou pela entidade supervisora da área de atuação correspondente à atividade fomentada.

Cabe destacar que o Partido dos Trabalhadores (PT) e o Partido Democrático Trabalhista (PDT) ajuizaram uma Ação Direta de Inconstitucionalidade (ADI) $\mathrm{n}$. 1.923/DF, no Supremo Tribunal Federal (STF), na íntegra, da Lei n. 9.637/1998, e, ainda, um pedido de declaração de inconstitucionalidade da redação do art. 24, XXIV, da Lei n. 8.666/1993, conferida pela Lei n. 9.648/1998, prevendo a dispensa de licitação "[...] para a celebração de contratos de prestação de serviços com as organizações sociais, qualificadas no âmbito das respectivas esferas de governo, para atividades contempladas no contrato de gestão.” (BRASIL, 2015).

O PT e o PDT alegaram que a lei das OSs feria os seguintes preceitos constitucionais: a criação das OSs configuraria apenas uma tentativa de escapar do regime jurídico de direito público, violação à impessoalidade e interferência indevida do Estado em associações; descumprimento do dever de licitação, pois a lei prevê que a permissão de uso de bem público poderá ser outorgada às OSs, pelo Poder Público, com dispensa de licitação; ofensa aos princípios da legalidade e do concurso público na gestão de pessoal; descumprimento de direitos previdenciários dos servidores; insubmissão a controles externos, ou seja, do Tribunal de Contas da União (TCU); e a restrição da atuação do Ministério Púbico, ao condicionar a determinados requisitos a atuação fiscalizadora do MP sobre as OSs - gravidade dos fatos e interesse público.

$\mathrm{O}$ voto do relator Ayres Britto foi pela inexistência de ofensa à Constituição Federal, de modo que a ADI foi julgada parcialmente procedente. $\mathrm{O}$ relator apenas determinou que os procedimentos de qualificação, a celebração do contrato de gestão, os contratos a serem celebrados pela OS com terceiros, com recursos públicos para seleção de 
Artigo

doi: $10.20396 /$ rho.v18i3.8651788

pessoal pelas OSs, fossem conduzidos de forma pública, objetiva e impessoal. Por fim, o relator determinou afastar qualquer interpretação que restrinja o controle, pelo Ministério Público e pelo TCU, da aplicação de verbas públicas pelas OSs.

Mesmo depois da renúncia do ex-presidente Fernando Collor, a política neoliberal continuou em curso com os ex-presidentes Itamar Franco, Fernando Henrique Cardoso, Luiz Inácio Lula da Silva, Dilma Rousseff. No atual governo de Michel Temer, essa ideologia econômica vem recrudescendo.

\section{AS ORGANIZAÇÕES SOCIAIS E SUA IMPLANTAÇÃO NA EDUCAÇÃO BÁSICA DE GOIÁS}

A política de desestatização ensejada pelo Governo Federal chega ao estado de Goiás por meio de medidas voltadas para a privatização das empresas públicas. No final da década de 1990, com a assunção de Marconi Ferreira Perillo Júnior, do Partido da Social Democracia Brasileira (PSDB), são implementadas medidas de reestruturação do Governo Estadual, tais como: ajuste fiscal, suposta valorização do servidor público e atendimento ao cidadão.

No que se refere à implantação das OSs no serviço público, em 2014, o governador Marconi Perillo alterou a Lei estadual n. 15.503, de 28 de dezembro de 2005, que dispõe sobre a qualificação de entidades como OSs estaduais e disciplina o procedimento de chamamento e seleção públicos, pela Lei n. 18.658, de 2 de outubro. A referida alteração incluiu, entre outras áreas, a educação como campo para a atuação das OSs, o que denotou a preocupação do governo em abrir, do ponto de vista legal, a possibilidade de implantar a gestão compartilhada por via das OSs na educação pública estadual. Cabe ressaltar que, a partir da vigência da lei supramencionada, o governo estadual iniciou o processo de gestão compartilhada na área da saúde.

Em 14 de outubro de 2015, o governador editou o Decreto n. 8.469, dispondo sobre medidas a serem adotadas por uma Comissão Especial para selecionar OSs estaduais para celebração de contratos de gestão, em 200, das 1.151 escolas da rede estadual durante o ano de 2016, ou seja, 30\% das unidades escolares que integram as Subsecretarias de Goiânia, Aparecida de Goiânia, Anápolis, Trindade e as do Entorno do Distrito Federal, como um Projeto-Piloto. Desde então, profissionais da educação, sindicato, alunos secundaristas, universidades, Ministério Público Estadual, entre outros, vêm se posicionando contra a adoção da gestão compartilhada e/ou contra os procedimentos adotados para a seleção das OSs.

Meses depois de anunciar a gestão compartilhada, por meio das OSs nas subsecretarias citadas, o governador altera o supracitado projeto e decide implantar a gestão compartilhada somente em $30 \%$ das Unidades Escolares da Macrorregião IV de 
Artigo

doi: $10.20396 /$ rho.v18i3.8651788

Anápolis (Abadiânia, Alexânia, Anápolis, Nerópolis e Pirenópolis), ou seja, em 23 escolas, com um total de 16.016 alunos. Ainda em 2015, o governador deu continuidade ao processo de implementação da gestão compartilhada, por meio do Decreto n. 8.441, de 28 de agosto de 2015, que institui Grupo de Trabalho com a finalidade de proceder às medidas necessárias para a celebração de contratos de gestão com OSs na área de educação.

Em 2016, o governo lançou o Edital de Chamamento Público n. 001/2016 destinado à seleção de organização social, qualificada em educação, tendo como objetivos o gerenciamento, a operacionalização e a execução das atividades administrativas, de apoio para a implantação e implementação de políticas pedagógicas definidas pela Seduce nas Unidades Educacionais da Rede Pública Estadual de Ensino, Macrorregião IV Anápolis. Depois de intensas manifestações, o Ministério Público do Estado de Goiás (MP-GO) propôs ação na Justiça pedindo a suspensão do edital de chamamento das OSs.

Ainda no âmbito da Seduce, foi lançado o Edital de Chamamento n. 002/2016, que dispunha da seleção de OS de Cultura (OSC), com vistas à transferência da produção, do gerenciamento, da operacionalização e da execução das atividades artísticas, culturais e sociais inerentes à Orquestra Filarmônica de Goiás (OFG). Um contrato que tinha como valor global $\mathrm{R} \$ 27.561 .760,00$ para serem repassados para a OS em quatro anos, sendo cada parcela anual no valor de $\mathrm{R} \$ 6.890 .440,00$.

Contudo, ao analisar a Lei Orçamentária Anual (LOA) de 2016, só foram encontradas previsões de despesas no valor total de $\mathrm{R} \$ 4.040 .000,00$ no Programa Incentivo à Cultura do Centro Cultural Oscar Niemeyer e no Programa Bolsa Futuro Inovador com a OFG. Ao comparar o valor previsto para despesas no exercício de 2016 e as despesas previstas com a OS, para o exercício de 2017, constata-se que a OS receberia $\mathrm{R}$ \$ 2.850.440,00 a mais para gerir a OFG. Essa disparidade entre a previsão orçamentária do governo estadual com a OFG e o que está previsto para repassar para OS fere explicitamente o princípio constitucional da economicidade.

Obviamente, essa análise necessitaria de mais detalhamentos financeiros, orçamentários e jurídicos, porém, a priori, essa parceria não demonstra que o governo terá eficiência na gestão financeira e na execução orçamentária e uma melhor qualidade neste serviço público através da gestão compartilhada com a OS. Destaca-se que o Chamamento n. 002/2016 foi revogado pelo governo que lançou o Chamamento Público n. 003, em 2017, tendo como vencedora a Organização Social Cultural Elysium Sociedade Cultural. Um contrato que tem como valor global $\mathrm{R} \$ 26.800 .000,00$ para serem repassados para a OS em cinco anos. No primeiro ano a OSC receberá $\mathrm{R} \$ 4.050 .814,25$, no segundo, terceiro e quarto receberá $\mathrm{R} \$$ 6.7000.000,00, e no último $\mathrm{R} \$ 2.639 .186,00$.

A Secretaria de Estado de Desenvolvimento Econômico, Científico e Tecnológico e de Agricultura, Pecuária e Irrigação (SED) lançou, em 2016, os Chamamentos Públicos n. 05, 06, 07, 08 e 09 para celebração de Contrato de Gestão, objetivando transferir a 
administração dos equipamentos públicos integrantes da Rede Pública Estadual de Educação Profissional e Tecnológica (Rede Itego), composta por Institutos Tecnológicos do Estado de Goiás (ITEGOs), e suas unidades vinculadas, os Colégios Tecnológicos (Cotecs), para as OSs.

Para implementar a gestão compartilhada na Rede Itego, a SED, através dos chamamentos, previu um orçamento de mais de $\mathrm{R} \$ 450$ milhões distribuídos durante 4 anos. As OSs selecionadas para gerenciar os Itegos e Cotecs de maneira compartilhada com a SED são: Instituto Brasileiro de Cultura, Educação, Desporto e Saúde (Ibraceds); Fundação Antares de Ensino Superior, Pós-Graduação, Pesquisa e Extensão (Faesp); Instituto Reger de Educação, Cultura e Tecnologia (Instituto Reger); Centro de Gestão em Educação Continuada (Cegecon); e Centro de Soluções em Tecnologia e Educação (Centeduc). Há quase um ano de gestão compartilhada já é possível notar os efeitos nefastos das OSs na educação tecnológica. Segundo dados do site das instituições quatro das cinco organizações compraram por $\mathrm{R} \$ 40$ milhões um software para ofertar cursos on line à distância, contudo o MEC oferece gratuitamente o Moodle para este tipo de atividade que inclusive já é utilizado pela SED.

Na Seduce, após a suspenção do Edital de Chamamento Público n. 001/2016, o governador enviou para a Assembleia Legislativa do Estado de Goiás (Alego) um projeto de lei para alterar a Lei n. 15.503 (Lei das OS) sob a justificativa de que as alterações melhorariam a lei tanto no aspecto jurídico como social. Entre as alterações destacam-se: a específica qualificação profissional do corpo técnico e diretivo da OS; a proibição de participação no Conselho de Administração em diretorias da OS de cônjuges, companheiros ou parentes, consanguíneos ou por afinidade, até o $3^{\circ}$ grau do governador, vice-governador, secretários de Estado, presidentes de autarquias e fundações, senadores, deputados federais e estaduais, membros do Judiciário, do Ministério Público, de Tribunais de Contas do Estado e dos Municípios, além do quadro de direção de quaisquer órgãos das administrações direta e indireta; a proibição de membros de conselho e diretores, estatutários ou não, de OS na estrutura de mais de uma entidade qualificada no Estado de Goiás; a limitação da remuneração dos membros da diretoria ao que percebe o governador; a impossibilidade de formalizar o contrato de gestão com entidades que tenham entre seus dirigentes, ou como membro do Conselho de Administração e Conselho Fiscal, componente cujas contas relativas à aplicação de recursos públicos tenham sido julgadas irregulares ou rejeitadas por Tribunal ou Conselho de Contas de qualquer esfera da Federação no período de oito anos, e seja julgado responsável por falta grave e inabilitada para o exercício de cargo de provimento em comissão, considerada responsável por ato de improbidade, ainda que não transitada em julgado a decisão condenatória, que tenha sido responsabilizada ou condenada pela prática de infração penal, civil ou administrativa.

Ao não permitir o nepotismo, o clientelismo na escolha das OSs, ao limitar a remuneração dos membros das OS e de implantar critérios que permitam escolher OSs 
com membros idôneos, o governador esperava acatar as recomendações do MP-GO e arrefecer o clima de contrariedade de parte da justiça, da sociedade e dos movimentos sociais em relação à implantação da gestão compartilhada na educação básica pelo menos no plano legal.

Além disso, foi firmada uma parceria entre governo do Estado e Banco Mundial através de um termo de cooperação, com o objetivo de desenvolver e implementar de maneira eficiente o projeto de gestão compartilhada com as OSs na rede estadual de ensino. A Seduce também contratou por 12 meses a empresa privada de consultoria Instituto Publix, com dispensa de licitação com valor global de R 700 mil para assessorar a implantação da gestão compartilhada através das OSs.

Contudo, na prática, essas medidas não foram tão eficazes, pois o Edital de Chamamento Público n. 003/2016 continha várias ilegalidades, além disso, das cinco OSs que participaram do processo de seleção do Chamamento, segundo um levantamento realizado pelo professor Rafael Saddi, da Universidade Federal de Goiás, três estão diretamente vinculadas ao governador e têm sócios ou ex-sócios envolvidos em corrupção com membros do Governo do Estado, e a única OS que não tem vínculo direto com o governador é formada por dono de escolas privadas, que entendem a educação como negócio e que não tem histórico nenhum de filantropia. (SINDICATO NACIONAL DOS DOCENTES DAS INSTITUIÇÕES DE ENSINO SUPERIOR, 2016).

Participaram do processo de seleção cinco OSE: Associação Grupo Tático de Resgate (GTR), Instituto Brasileiro de Cultura, Educação, Desporto e Saúde (Ibraceds) e Instituto de Educação, Cultura e Meio Ambiente (ECMA) e Instituto de Educação e Cidadania (IEC) e Instituto Destra de Educação (INDED). A OSE vencedora do processo de análise das propostas técnicas foi a GTR que totalizou 70,1 pontos. A GTR foi fundada em maio de 2009, tendo sua sede na cidade de Goiânia, Goiás. Segundo seu Cadastro Nacional da Pessoa Jurídica (CNPJ), a maioria das áreas de atividades é relacionada à área da saúde. O presidente José Roldão Gonçalves Barbosa da GTR é professor da Pontifícia Universidade Católica de Goiás (PUC-GO) nas áreas de matemática, computação e engenharia e diretor administrativo-financeiro da Santa Casa de Misericórdia de Goiânia. José Roldão é filiado, desde 2009, ao Partido da Social Democracia Brasileira (PSDB), mesmo partido político do governador Marconi Perillo.

O ex-presidente da GTR era o médico André Luiz Braga, que foi investigado pelo Ministério Público do Estado de Goiás (MP-GO) por fraude nos fundos rotativos dos hospitais estaduais, em 2011. Outro sócio da GTR era Antônio Carlos Coelho Noleto, que, segundo o professor Rafael Saddi (2016):

[...] conforme matéria da Revista Nova Escola, "é membro do PSDB/GO, servidor da Assembleia Legislativa do Estado de Goiás cedido para a 
governadoria de julho a dezembro do ano passado e beneficiário de suspensão de processo em razão da prática do crime de concussão".

Segundo o Ministério Público, o delito praticado por Antônio Carlos Coelho Noleto foi realizado "à época em que ele estava cedido para o Departamento de Fiscalização da Agência Goiana de Regulação, Controle e Fiscalização (AGR)”.

Com relação à atuação na área da educação, a GTR informou à Revista Nova Escola que a organização já atendeu cerca de 300 estudantes de 4 a 14 anos com a ação Brincar para Aprender. Além disso, o conselho administrativo é composto por "[...] exreitores de universidades públicas e privadas, diretores de cursos de graduação técnica e superior, membros de conselhos estaduais de educação, professores e ex-professores de ensino superior." (NOVA ESCOLA, 2016).

A OSE selecionada foi acusada do crime de plágio, pois parte da proposta técnica apresentada à Seduce foi copiada de outros documentos sem citação da fonte. Segundo matéria publicada pelo jornal O Popular, das 801 páginas da proposta técnica, em 65 páginas foram detectados trechos de documentos já publicados, desde manuais até projetos universitários. No dia 27 de dezembro de 2016, dois dias após o Natal, a secretária Raquel Teixeira homologou a seleção da GTR como entidade selecionada para o contrato de gestão compartilhada das 23 Unidades Educacionais de Goiás com valor total de quase R\$ 70 milhões.

Com objetivo de obter uma liminar para o cancelamento do Chamamento Público n. 003/2016, até que se realizassem as adequações recomendadas pelo MP-GO, a promotora de Justiça Carla Brant propôs ação civil pública contra o Estado de Goiás e a Seduce, em razão de irregularidades e inconstitucionalidade no edital. Segundo a promotora, há três aspectos ilegais no edital: a contratação de professores pelo regime celetista, o repasse de verba do Fundo de Manutenção e Desenvolvimento da Educação Básica e de Valorização dos Profissionais da Educação (Fundeb) à OS e a falta de comprovação da economicidade da contratação para gerir as unidades escolares. (MINISTÉRIO PÚBLICO DO ESTADO DE GOIÁS, 2016b).

Com o imbróglio jurídico acerca da Chamada Pública n. 003/2016, em janeiro de 2017, a Seduce anunciou o lançamento de dois Chamamentos Públicos, n. 001 e n. 002. O primeiro se destina à celebração de contrato de gestão para as Unidades Educacionais da Rede Pública Estadual de Ensino da Macrorregião VIII - Águas Lindas/Planaltina, que conta com 41 unidades escolares e 32.843 alunos dos quais 11 unidades escolares e 12.000 estudantes formarão o projeto-piloto para a gestão compartilhada. O segundo se destinará às Unidades Educacionais da Rede Pública Estadual de Ensino da Macrorregião V Luziânia/Novo Gama, que conta com 60 unidades escolares e 42.635 alunos dos quais 14 unidades escolares e 13.500 alunos formarão o projeto-piloto para a gestão compartilhada.

Ao que tudo indica, o governo de Goiás acredita que não conseguirá reverter a situação que o impede de formalizar o contrato de gestão do Chamamento Público n. 
Artigo

doi: $10.20396 /$ rho.v18i3.8651788

003/2016 e já se prepara para implantar a gestão compartilhada através de dois novos chamamentos que envolverão 25 unidades escolares e 25.500 alunos das Macrorregiões VIII e V. Até o presente momento, apenas a Macrorregião VIII teve lançado o Chamamento Público n. 001/2017. O vencedor do Chamamento Público n. 001/2017 foi a OSE Instituto Destra de Educação (Inded).

O Inded foi fundado legalmente, em 1. ${ }^{\circ}$ de dezembro de 2015, pouco mais de dois meses após a criação do decreto que permitiu a celebração de contrato de gestão com OS na educação estadual. O instituto Destra tinha ficado em último lugar na seleção para o Chamamento Público n. 001 de 2016. Por ordem judicial da juíza Patrícia Morais Costa Velasco, da comarca de Santo Antônio do Descoberto, o Chamamento Público n. 001/2017 foi suspenso. Com essa suspensão o governo já anuncia lançar novo edital para a implantação da gestão compartilhada na Macrorregião V, mas devido às eleições de 2018 o governo, provavelmente, não conseguirá implantar a gestão compartilhada neste mandato.

\section{UMA ANÁLISE SOBRE O FINANCIAMENTO DA EDUCAÇÃO PARA A GESTÃO COMPARTILHADA ATRAVÉS DA OSE PELOS CHAMAMENTOS PÚBLICOS N. 003/2016 E N. 001/2017}

Em pesquisa recentemente publicada na Revista Eletrônica de Educação (Reveduc) Souza e Flores (2017) analisam as questões do financiamento da educação no processo de implantação da gestão compartilhada pela Seduce através da análise do Chamamento Público n. 001 de 2016. Portanto, esta pesquisa se delimitará à análise do financiamento da educação no processo de implantação da gestão compartilhada nos Chamamentos Públicos n. 003/2016 e n. 001/2017, que foram lançados após o fracasso do chamamento anteriormente citado.

A priori, é importante destacar que a aplicação devida dos recursos na educação é um desafio para a maioria dos governos, seja porque a legislação é confusa, omissa ou contraditória, seja pela corrupção que corrói os recursos públicos ou pela dificuldade técnica de se entender sobre o assunto. Isto fica evidente ao se analisar os relatórios das contas dos governos, elaborados pela equipe técnica dos Tribunais de Contas, no que se refere à educação.

Davies (2010), ao analisar os relatórios de contas, bem como os documentos legais sobre financiamento da educação, em Goiás, constatou, entre outros aspectos, erros graves na contabilização da receita e das despesas em educação. Por exemplo, o governo não contabilizou alguns impostos e transferências na Manutenção e Desenvolvimento do Ensino (MDE); por outro lado, contabilizou ilegalmente despesas com merenda, convênios, bolsas universitárias, entre outras, para a MDE. O cancelamento de despesas empenhadas de um exercício financeiro para outro e os custos com inativos e pensionistas dentro do percentual mínimo de recurso para a MDE também foram aspectos levantados 
pelo pesquisador. O pouco detalhamento das despesas e a maneira genérica da prestação de contas foram apontados pelo autor como um empecilho para a fiscalização dos recursos da educação estadual.

Diante das dificuldades, e até mesmo ilegalidades na aplicação dos recursos públicos para a educação é bem provável que a gestão compartilhada aprofunde tais dificuldades, uma vez que nem mesmo o governo tem, durante anos, conseguido aplicar devidamente os recursos na educação pública. Além disso, nem mesmo o Tribunal de Contas do Estado de Goiás (TCE-GO) acredita que a gestão compartilhada é uma opção eficiente para a educação estadual: "[...] a transferência da gestão de unidades escolares integrantes da rede pública estadual de ensino para OS não tem se mostrado ainda como uma opção eficiente para o Estado." (GOIÁS, 2016d, p. 292).

É importante destacar que, entre os princípios da administração pública, está previsto, na Constituição Federal de 1988, o da economicidade, que trata da obtenção do melhor resultado estratégico possível de uma determinada alocação de recursos financeiros, econômicos e/ou patrimoniais em um dado cenário socioeconômico. Contudo, segundo o Chamamento Público n. 003/2016, ao se comparar o desembolso atual das 23 unidades escolares com o desembolso estimado com o contrato de gestão, o governo estadual feriu o princípio da economicidade, uma vez que o gasto total das unidades escolares sem o contrato de gestão ficaria em, aproximadamente, $R \$ 56$ milhões e, com o contrato de gestão, o governo estimou em, aproximadamente, $R \$ 70$ milhões, ou seja, uma diferença de mais de $\mathrm{R} \$ 14$ milhões, conforme se constata no anexo $\mathrm{V}$ do chamamento.

O Chamamento Público n. 003/2016, em seu anexo VII, que contém a Minuta do Contrato de Gestão, no item 7.2 da cláusula sétima, que trata dos recursos financeiros, dizia que o valor global do contrato poderia sofrer alteração, sendo assim, o valor estipulado que foi de, aproximadamente, $\mathrm{R} \$ 70$ milhões poderia ser elevado desde que observadas as disponibilidades financeiras. Haja vista que havia na LOA 2016 a previsão de mais de $\mathrm{R} \$ 528$ milhões para a gestão compartilhada, provavelmente, o governo excederia o valor estipulado para a OS que assumisse a gestão compartilhada das unidades educacionais. Além disso, o item 10.1 da minuta previa a possibilidade de alteração do contrato de gestão tanto em aspecto qualitativo quanto quantitativo através de termos aditivos. Abaixo seguem os valores dos recursos que foram orçados para a gestão compartilhada para o exercício de 2016: 
Tabela 01 - Orçamento da Secretaria Estadual de Educação, Cultura e Esporte de 2016

FONTE ORÇAMENTÁRIA - 2016 (R\$)

\begin{tabular}{|c|c|c|c|c|c|}
\hline $\begin{array}{l}\text { GRUPO } \\
\text { DE } \\
\text { DESPESA }\end{array}$ & $\begin{array}{c}\text { 00 - Receitas } \\
\text { Ordinárias } \\
\text { (Gestão } \\
\text { Compartilhad } \\
\text { a - OS) }\end{array}$ & $\begin{array}{l}\text { 08 - Recursos } \\
\text { do Fundeb } \\
\text { (Gestão } \\
\text { Compartilhad } \\
\text { a - OS) }\end{array}$ & $\begin{array}{l}\text { 09 - Cota- } \\
\text { Parte do } \\
\text { Salário } \\
\text { Educação - } \\
\text { Cota } \\
\text { Federal } \\
\text { (Gestão } \\
\text { Compartilh } \\
\text { ada - OS) }\end{array}$ & $\begin{array}{l}16 \text { - Cota- } \\
\text { Parte do } \\
\text { Salário- } \\
\text { Educação - } \\
\text { Cota } \\
\text { Estadual } \\
\text { (Gestão } \\
\text { Compartilh } \\
\text { ada - OS) }\end{array}$ & TOTAL \\
\hline $\begin{array}{l}\text { Pessoal e } \\
\text { Encargos } \\
\text { Sociais }\end{array}$ & $60.000,00$ & $\begin{array}{c}300.040 .000,0 \\
0\end{array}$ & & & $\begin{array}{l}\text { 300.100.000, } \\
00\end{array}$ \\
\hline $\begin{array}{l}\text { Outras } \\
\text { Despensas } \\
\text { Correntes }\end{array}$ & $160.050 .000,00$ & $60.000,00$ & $\begin{array}{c}18.000 .000,0 \\
0\end{array}$ & $\begin{array}{c}30.050 .000,0 \\
0\end{array}$ & $\begin{array}{c}\text { 208.160.000, } \\
00\end{array}$ \\
\hline $\begin{array}{l}\text { Investiment } \\
\text { os }\end{array}$ & $10.050 .000,00$ & $60.000,00$ & & $\begin{array}{c}10.050 .000,0 \\
0\end{array}$ & $\begin{array}{c}20.160 .000,0 \\
0\end{array}$ \\
\hline TOTAL & 170.160.000,00 & $\begin{array}{c}300.160 .000,0 \\
0\end{array}$ & $\begin{array}{c}18.000 .000,0 \\
0\end{array}$ & $\begin{array}{c}40.100 .000,0 \\
0\end{array}$ & $\begin{array}{c}\text { 528.420.000, } \\
00\end{array}$ \\
\hline
\end{tabular}

Fonte: GOIÁS, 2016c. Tabela elaborada pelos autores.

Nos orçamentos de 2016 e 2017, inicialmente, o Decreto n. 8.469 de 2015 previa a implantação da gestão compartilhada em 200 unidades escolares, mas o Chamamento Público n. 001 de 2016 reduziu a implantação para 23 unidades escolares. Ao fracassar, a Seduce lançou outro Chamamento Público de n. 003, ainda em 2016, para implantar a gestão compartilhada em 23 unidades escolares. Por fim, após os questionamentos jurídicos, a Seduce lançou um novo chamamento, em 2017, para implantar o projeto em 11 unidades escolares.

Porém o governo elaborou a LOA de 2016, prevendo aplicar mais de meio bilhão para a implantação da gestão compartilhada, conforme dados da Tabela I. Tal valor se explicava pelo fato de o projeto inicial (previsto no Decreto n. 8.469) prever a implantação em 200 unidades escolares. Mas, em 2017, o governador aumentou o valor previsto para o repasse à OSE para mais de $\mathrm{R} \$ 740$ milhões, conforme a Tabela 02, mesmo prevendo implantar o projeto em apenas 25 unidades escolares, segundo os Chamamentos n. $001 \mathrm{e} \mathrm{n}$. 002 de 2017. Tendo como orçamento geral anual o valor de $\mathrm{R} \$ 2.692 .989 .000,00$, é inexplicável que o governo reserve $28 \%$ desse orçamento para manter apenas $2 \%$ das unidades escolares. 
Tabela 02 - Orçamento da Secretaria Estadual de Educação, Cultura e Esporte de 2017

\begin{tabular}{|c|c|c|c|c|c|c|}
\hline & \multicolumn{6}{|c|}{ FONTE ORÇAMENTÁRIA - 2017 (R\$) } \\
\hline $\begin{array}{c}\text { GRUPO DE } \\
\text { DESPESA }\end{array}$ & $\begin{array}{c}100- \\
\text { Receitas } \\
\text { Ordinárias } \\
\text { (Gestão } \\
\text { Compartilha } \\
\text { da - OS) }\end{array}$ & $\begin{array}{c}108- \\
\text { Recursos do } \\
\text { Fundeb } \\
\text { (Gestão } \\
\text { Compartilha } \\
\text { da - OS) }\end{array}$ & $\begin{array}{l}109 \text { - Cota- } \\
\text { Parte do } \\
\text { Salário } \\
\text { Educação - } \\
\text { Cota Federal } \\
\text { (Gestão } \\
\text { Compartilha } \\
\text { da -OS) }\end{array}$ & $\begin{array}{c}116 \text { - Cota- } \\
\text { Parte do } \\
\text { Salário- } \\
\text { Educação - } \\
\text { Cota } \\
\text { Estadual } \\
\text { (Gestão } \\
\text { Compartilha } \\
\text { da - OS) }\end{array}$ & $\begin{array}{c}282- \\
\text { Convênios } \\
\text { outros }\end{array}$ & TOTAL \\
\hline $\begin{array}{l}\text { Pessoal e } \\
\text { Encargos } \\
\text { Sociais }\end{array}$ & $30.000,00$ & $\begin{array}{c}520.000 .000 \\
00\end{array}$ & & & & $\begin{array}{c}\mathbf{5 2 0 . 0 3 0 . 0 0} \\
\mathbf{0 , 0 0}\end{array}$ \\
\hline $\begin{array}{l}\text { Outras } \\
\text { Despensas } \\
\text { Correntes }\end{array}$ & $\begin{array}{c}190.000 .000 \\
00\end{array}$ & $30.000,00$ & $\begin{array}{c}15.000 .000,0 \\
0\end{array}$ & $\begin{array}{c}10.020 .000,0 \\
0\end{array}$ & $10.000,00$ & $\begin{array}{c}215.050 .00 \\
0,00\end{array}$ \\
\hline Investimentos & $4.020 .000,00$ & $30.000,00$ & & $3.020 .000,00$ & $10.000,00$ & $\begin{array}{c}7.070 .000 \\
00\end{array}$ \\
\hline TOTAL & $\begin{array}{c}\text { 194.050.000, } \\
00 \\
\end{array}$ & $\begin{array}{c}520.060 .000 \\
00 \\
\end{array}$ & $\begin{array}{c}15.000 .000,0 \\
0\end{array}$ & $\begin{array}{c}13.040 .000,0 \\
0\end{array}$ & $\mathbf{2 0 . 0 0 0 , 0 0}$ & $\begin{array}{c}42.170 .00 \\
0,00 \\
\end{array}$ \\
\hline
\end{tabular}

Fonte: GOIÁS, 2017b. Tabela elaborada pelo autor.

Outro aspecto importante sobre o financiamento da educação básica e o processo de implantação das OSs na educação estadual diz respeito aos recursos do Programa Dinheiro Direto na Escola (PDDE) repassados pelo Fundo Nacional de Desenvolvimento da Educação (FNDE/MEC). Segundo levantamento realizado no site do FNDE, em 2016, todas as escolas previstas no Chamamento Público n. 003/2016 receberam recursos do PDDE. Ao todo as escolas receberam mais de R\$ 1,3 milhão, segundo a Tabela 03; contudo, o Chamamento Público não fez menção à gestão desses recursos.

A Seduce não definiu de que maneira esses recursos seriam gerenciados na gestão compartilhada e nem ao menos levou os recursos em consideração, a título de elaborar as regras para o contrato de gestão. Nem mesmo o Ministério Público do Estado de Goiás (MPOG) e o TCE-GO questionaram o governo acerca da utilização dos recursos do PDDE através da gestão compartilhada.

Tabela 03 - Relação das Unidades Executoras do PDDE da macrorregião IV, em 2016. Valores nominais $(\mathrm{R} \$)$.

\begin{tabular}{rlcccc|c}
\hline Município & $\begin{array}{c}\text { Relação de } \\
\text { Unidades } \\
\text { Executoras }\end{array}$ & PDDE & $\begin{array}{c}\text { PDDE } \\
\text { Estrutura }\end{array}$ & $\begin{array}{c}\text { PPDE } \\
\text { Qualidade }\end{array}$ & $\begin{array}{c}\text { PDDE } \\
\begin{array}{c}\text { Educ. } \\
\text { Integral }\end{array}\end{array}$ & $\begin{array}{c}\text { Total } \\
\text { recebido }\end{array}$ \\
\cline { 6 - 7 } & (REx) - 2016 & Total & Total & Total & Total & \\
\cline { 1 - 2 } ABADIÂNIA & COLÉGIO & $\mathrm{R} \$$ & & $\mathrm{R} \$$ & $\mathrm{R} \$$ & $\mathrm{R} \$ 87.576,00$ \\
& ESTADUAL & $27.640,00$ & & $50.000,00$ & $9.936,00$ & \\
\hline
\end{tabular}


Tabela 03 - Relação das Unidades Executoras do PDDE da macrorregião IV, em 2016. Valores nominais $(\mathrm{R} \$)$.

\begin{tabular}{|c|c|c|c|c|c|c|}
\hline & $\begin{array}{l}\text { OSÓRIO } \\
\text { RODRIGUES } \\
\text { CAMARGO }\end{array}$ & & & & & (continuação) \\
\hline ALEXÂNIA & $\begin{array}{l}\text { COLÉGIO } \\
\text { ESTADUAL } 31 \\
\text { DE MARÇO }\end{array}$ & $\begin{array}{l}\mathrm{R} \$ \\
20.000,00^{*}\end{array}$ & & & & $\mathrm{R} \$ 20.000,00$ \\
\hline ANÁPOLIS & $\begin{array}{l}\text { COLÉGIO } \\
\text { ESTADUAL } \\
\text { AMERICO } \\
\text { BORGES DE } \\
\text { CARVALHO }\end{array}$ & $\begin{array}{l}\mathrm{R} \$ \\
14.100,00\end{array}$ & $\begin{array}{l}\mathrm{R} \$ \\
12.500,00\end{array}$ & $\begin{array}{l}\mathrm{R} \$ \\
40.000,00\end{array}$ & $\begin{array}{l}\mathrm{R} \$ \\
12.708,00\end{array}$ & $\mathrm{R} \$ 79.308,00$ \\
\hline ANÁPOLIS & $\begin{array}{l}\text { COLÉGIO } \\
\text { ESTADUAL } \\
\text { ANTENSINA } \\
\text { SANTANA }\end{array}$ & $\begin{array}{l}\mathrm{R} \$ \\
26.120,00\end{array}$ & & $\begin{array}{l}\mathrm{R} \$ \\
60.000,00\end{array}$ & $\begin{array}{l}\mathrm{R} \$ \\
12.708,00\end{array}$ & $\mathrm{R} \$ 98.828,00$ \\
\hline ANÁPOLIS & $\begin{array}{l}\text { COLÉGIO } \\
\text { ESTADUAL } \\
\text { CARLOS DE } \\
\text { PINA }\end{array}$ & $\begin{array}{l}\mathrm{R} \$ \\
8.100,00\end{array}$ & $\begin{array}{l}\mathrm{R} \$ \\
10.000,00\end{array}$ & $\begin{array}{l}\mathrm{R} \$ \\
30.000,00\end{array}$ & $\begin{array}{l}\mathrm{R} \$ \\
14.328,00\end{array}$ & $\mathrm{R} \$ 62.428,00$ \\
\hline ANÁPOLIS & $\begin{array}{l}\text { COLÉGIO } \\
\text { ESTADUAL } \\
\text { GENERAL } \\
\text { CURADO }\end{array}$ & $\begin{array}{l}\mathrm{R} \$ \\
21.580,00\end{array}$ & & $\begin{array}{l}\mathrm{R} \$ \\
40.000,00\end{array}$ & $\begin{array}{l}\mathrm{R} \$ \\
9.936,00\end{array}$ & $\mathrm{R} \$ 71.516,00$ \\
\hline ANÁPOLIS & $\begin{array}{l}\text { COLÉGIO } \\
\text { ESTADUAL } \\
\text { GOMES DE } \\
\text { SOUZA } \\
\text { RAMOS }\end{array}$ & $\begin{array}{l}\mathrm{R} \$ \\
18.280,00\end{array}$ & & $\begin{array}{l}\mathrm{R} \$ \\
50.000,00\end{array}$ & $\begin{array}{l}\mathrm{R} \$ \\
16.956,00\end{array}$ & $\mathrm{R} \$ 85.236,00$ \\
\hline ANÁPOLIS & $\begin{array}{l}\text { COLÉGIO } \\
\text { ESTADUAL } \\
\text { HERTA } \\
\text { LAYSER } \\
\text { ODWYER }\end{array}$ & $\begin{array}{l}\mathrm{R} \$ \\
13.620,00\end{array}$ & & $\begin{array}{l}\mathrm{R} \$ \\
40.000,00\end{array}$ & $\begin{array}{l}\mathrm{R} \$ \\
14.328,00\end{array}$ & $\mathrm{R} \$ 67.948,00$ \\
\hline ANÁPOLIS & $\begin{array}{l}\text { COLÉGIO } \\
\text { ESTADUAL } \\
\text { JAD } \\
\text { SALOMÃO }\end{array}$ & $\begin{array}{l}\mathrm{R} \$ \\
4.640,00\end{array}$ & & $\begin{array}{l}\mathrm{R} \$ \\
20.000,00\end{array}$ & $\begin{array}{l}\mathrm{R} \$ \\
12.708,00\end{array}$ & $\mathrm{R} \$ 37.348,00$ \\
\hline ANÁPOLIS & $\begin{array}{l}\text { COLÉGIO } \\
\text { ESTADUAL } \\
\text { JOSÉ } \\
\text { LUDOVICO DE } \\
\text { ALMEIDA }\end{array}$ & $\begin{array}{l}\mathrm{R} \$ \\
15.460,00\end{array}$ & & $\begin{array}{l}\mathrm{R} \$ \\
40.000,00\end{array}$ & $\begin{array}{l}\mathrm{R} \$ \\
12.708,00\end{array}$ & $\mathrm{R} \$ 68.168,00$ \\
\hline ANÁPOLIS & $\begin{array}{l}\text { COLÉGIO } \\
\text { ESTADUAL } \\
\text { LEINY LOPES }\end{array}$ & $\begin{array}{l}\mathrm{R} \$ \\
17.420,00\end{array}$ & & $\begin{array}{l}\mathrm{R} \$ \\
40.000,00\end{array}$ & $\begin{array}{l}\mathrm{R} \$ \\
24.264,00\end{array}$ & $\mathrm{R} \$ 81.684,00$ \\
\hline
\end{tabular}


Tabela 03 - Relação das Unidades Executoras do PDDE da macrorregião IV, em 2016. Valores nominais $(\mathrm{R} \$)$.

\begin{tabular}{|c|c|c|c|c|c|}
\hline & DE SOUZA & & & & (continuação) \\
\hline ANÁPOLIS & $\begin{array}{l}\text { COLÉGIO } \\
\text { ESTADUAL } \\
\text { OSVALDO } \\
\text { FRANCISCO } \\
\text { DA SILVA - }\end{array}$ & $\begin{array}{l}\mathrm{R} \$ \\
9.260,00\end{array}$ & $\begin{array}{l}\mathrm{R} \$ \\
30.000,00\end{array}$ & $\begin{array}{l}\mathrm{R} \$ \\
9.936,00\end{array}$ & $\mathrm{R} \$ 49.196,00$ \\
\hline ANÁPOLIS & $\begin{array}{l}\text { COLÉGIO } \\
\text { ESTADUAL } \\
\text { PADRE } \\
\text { FERNANDO } \\
\text { GOMES DE } \\
\text { MELO }\end{array}$ & $\begin{array}{l}\mathrm{R} \$ \\
10.000,00^{*}\end{array}$ & & & $\mathrm{R} \$ 10.000,00$ \\
\hline ANÁPOLIS & $\begin{array}{l}\text { COLÉGIO } \\
\text { ESTADUAL } \\
\text { PLÍNIO JAIME }\end{array}$ & $\begin{array}{l}\mathrm{R} \$ \\
24.960,00\end{array}$ & $\begin{array}{l}\mathrm{R} \$ \\
60.000,00\end{array}$ & $\begin{array}{l}\mathrm{R} \$ \\
7.164,00\end{array}$ & $\mathrm{R} \$ 92.124,00$ \\
\hline ANÁPOLIS & $\begin{array}{l}\text { COLÉGIO } \\
\text { ESTADUAL } \\
\text { POLIVALENTE } \\
\text { FREI JOÃO } \\
\text { BATISTA }\end{array}$ & $\begin{array}{l}\mathrm{R} \$ \\
35.300,00\end{array}$ & $\begin{array}{l}\mathrm{R} \$ \\
70.000,00\end{array}$ & $\begin{array}{l}\mathrm{R} \$ \\
12.708,00\end{array}$ & $\begin{array}{l}\mathrm{R} \$ \\
118.008,00\end{array}$ \\
\hline ANÁPOLIS & $\begin{array}{l}\text { COLÉGIO } \\
\text { ESTADUAL } \\
\text { PROFESSOR } \\
\text { JOSÉ } \\
\text { ABDALLA }\end{array}$ & $\begin{array}{l}\mathrm{R} \$ \\
9.140,00\end{array}$ & $\begin{array}{l}\mathrm{R} \$ \\
30.000,00\end{array}$ & & $\mathrm{R} \$ 39.140,00$ \\
\hline ANÁPOLIS & $\begin{array}{l}\text { COLÉGIO } \\
\text { ESTADUAL } \\
\text { SENADOR } \\
\text { ONOFRE } \\
\text { QUINAN }\end{array}$ & $\begin{array}{l}\mathrm{R} \$ \\
16.500,00\end{array}$ & & & $\mathrm{R} \$ 16.500,00$ \\
\hline ANÁPOLIS & $\begin{array}{l}\text { COLÉGIO } \\
\text { ESTADUAL } \\
\text { VEREADOR } \\
\text { LUIZ DE } \\
\text { ALMEIDA }\end{array}$ & $\begin{array}{l}\mathrm{R} \$ \\
7.680,00\end{array}$ & & $\begin{array}{l}\mathrm{R} \$ \\
12.708,00\end{array}$ & $\mathrm{R} \$ 20.388,00$ \\
\hline ANÁPOLIS & $\begin{array}{l}\text { COLÉGIO } \\
\text { ESTADUAL } \\
\text { VIRGINIO } \\
\text { SANTILLO }\end{array}$ & $\begin{array}{l}\mathrm{R} \$ \\
10.000,00^{*}\end{array}$ & & & $\mathrm{R} \$ 10.000,00$ \\
\hline ANÁPOLIS & $\begin{array}{l}\text { COLÉGIO } \\
\text { ESTADUAL } \\
\text { ZECA } \\
\text { BATISTA }\end{array}$ & $\begin{array}{l}\mathrm{R} \$ \\
4.580,00\end{array}$ & $\begin{array}{l}\mathrm{R} \$ \\
20.000,00\end{array}$ & $\begin{array}{l}\mathrm{R} \$ \\
12.672,00\end{array}$ & $\mathrm{R} \$ 37.252,00$ \\
\hline NERÓPOLIS & $\begin{array}{l}\text { COLÉGIO } \\
\text { ESTADUAL }\end{array}$ & $\begin{array}{l}\mathrm{R} \$ \\
17.960,00\end{array}$ & $\begin{array}{l}\mathrm{R} \$ \\
50.000,00\end{array}$ & $\begin{array}{l}\mathrm{R} \$ \\
12.708,00\end{array}$ & $\mathrm{R} \$ 80.668,00$ \\
\hline
\end{tabular}


Tabela 03 - Relação das Unidades Executoras do PDDE da macrorregião IV, em 2016. Valores nominais $(\mathrm{R} \$)$.

\begin{tabular}{|c|c|c|c|c|c|c|}
\hline & $\begin{array}{l}\text { DOUTOR } \\
\text { NEGREIROS }\end{array}$ & & & & & \\
\hline PIRENÓPOLIS & $\begin{array}{l}\text { COLÉGIO } \\
\text { ESTADUAL } \\
\text { SENHOR DO } \\
\text { BONFIM }\end{array}$ & $\begin{array}{l}\mathrm{R} \$ \\
7.700,00\end{array}$ & & & $\begin{array}{l}\mathrm{R} \$ \\
12.708,00\end{array}$ & $\mathrm{R} \$ 20.408,00$ \\
\hline PIRENÓPOLIS & $\begin{array}{l}\text { ESCOLA } \\
\text { ESTADUAL } \\
\text { SANTO } \\
\text { AGOSTINHO }\end{array}$ & $\begin{array}{l}\mathrm{R} \$ \\
7.440,00\end{array}$ & & $\begin{array}{l}\mathrm{R} \$ \\
20.000,00\end{array}$ & $\begin{array}{l}\mathrm{R} \$ \\
24.264,00\end{array}$ & $\mathrm{R} \$ 51.704,00$ \\
\hline \multicolumn{2}{|c|}{ TOTAL } & $\begin{array}{l}\mathrm{R} \$ \\
\mathbf{3 4 7 . 4 8 0 , 0 0}\end{array}$ & $\begin{array}{l}\mathrm{R} \$ \\
22.500,00\end{array}$ & $\begin{array}{l}\mathrm{R} \$ \\
690.000,00\end{array}$ & $\begin{array}{l}\mathrm{R} \$ \\
245.448,00\end{array}$ & $\begin{array}{l}\mathrm{R} \$ \\
1.305 .428,00\end{array}$ \\
\hline
\end{tabular}

* Estimativa baseada no número de alunos das unidades escolares.

Fonte: Brasil, 2016. Tabela elaborada pelos autores.

O Chamamento Público n. 001 de 2017 também não foi claro em relação aos recursos do PDDE, aliás a confusão foi maior, pois o chamamento afirma que não repassará recursos do FNDE/MEC para a OSE. Sendo assim, não fica claro de que forma esses recursos serão gerenciados pela OSE, pois são repassados para uma conta bancária da unidade escolar e gerenciados pelo Conselho Escolar que define as prioridades para o uso dos recursos. Além disso, esse Conselho presta contas para o FNDE/MEC de todos os gastos com os recursos. As unidades escolares do Chamamento n. 001 de 2017 receberam quase R\$300 mil reais do PDDE, em 2016, conforme a Tabela 04.

Segundo o Chamamento Público (GOIÁS, 2017a, p. 34), a OSE terá que: “Garantir a efetiva atuação do Conselho Escolar nas decisões administrativas, financeiras e pedagógicas da respectiva unidade escolar na aplicação dos recursos oriundos do Programa Dinheiro Direto na Escola-PDDE/MEC;". Contudo, o chamamento não é claro sobre a participação dos integrantes da OSE na composição do Conselho Escolar. Além disso, para Adrião e Peroni (2007) a participação da comunidade na gestão dos recursos do PDDE já é insuficiente, sobretudo, pelo Programa não pressupor para sua realização a efetiva democratização da gestão da esfera pública.

Tabela 04 - Relação das Unidades Executoras do PDDE da macrorregião VIII, em 2016. Valores nominais $(\mathrm{R} \$)$.

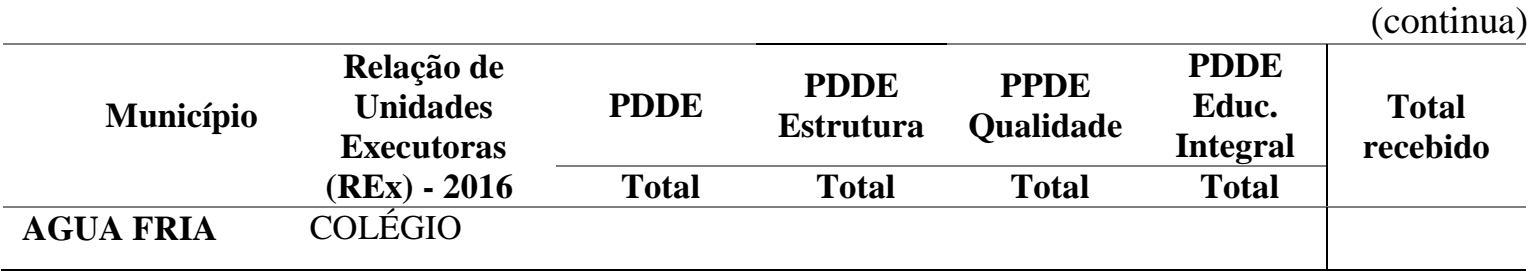


Tabela 04 - Relação das Unidades Executoras do PDDE da macrorregião VIII, em 2016. Valores nominais $(\mathrm{R} \$)$.

\begin{tabular}{|c|c|c|c|c|c|}
\hline DE GOIÁS & $\begin{array}{l}\text { ESTADUAL } \\
\text { ÁGUA FRIA }\end{array}$ & & & & (continuação) \\
\hline $\begin{array}{l}\text { ÁGUAS } \\
\text { LINDAS DE } \\
\text { GOIÁS }\end{array}$ & $\begin{array}{l}\text { COLÉGIO } \\
\text { ESTADUAL } \\
\text { PRINCESA } \\
\text { DAIANA }\end{array}$ & $\begin{array}{l}\mathrm{R} \$ \\
35.200,00\end{array}$ & & & $\begin{array}{l}\mathrm{R} \$ \\
35.200,00\end{array}$ \\
\hline $\begin{array}{l}\text { ÁGUAS } \\
\text { LINDAS DE } \\
\text { GOIÁS }\end{array}$ & $\begin{array}{l}\text { COLÉGIO } \\
\text { ESTADUAL } \\
\text { JUSCELINO } \\
\text { KUBITSCHEK } \\
\text { DE OLIVEIRA }\end{array}$ & $\begin{array}{l}\mathrm{R} \$ \\
31.180,00\end{array}$ & & & $\begin{array}{l}\mathrm{R} \$ \\
31.180,00\end{array}$ \\
\hline $\begin{array}{l}\text { ÁGUAS } \\
\text { LINDAS DE } \\
\text { GOIÁS }\end{array}$ & $\begin{array}{l}\text { COLÉGIO } \\
\text { ESTADUAL } \\
\text { MANSÕES } \\
\text { ODISSÉIA }\end{array}$ & $\begin{array}{l}\mathrm{R} \$ \\
21.880,00\end{array}$ & & & $\begin{array}{l}\mathrm{R} \$ \\
21.880,00\end{array}$ \\
\hline $\begin{array}{l}\text { ÁGUAS } \\
\text { LINDAS DE } \\
\text { GOIÁS }\end{array}$ & $\begin{array}{l}\text { COLÉGIO } \\
\text { ESTADUAL } \\
\text { MACHADO } \\
\text { DE ASSIS }\end{array}$ & $\begin{array}{l}\mathrm{R} \$ \\
23.780,00\end{array}$ & & & $\begin{array}{l}\mathrm{R} \$ \\
23.780,00\end{array}$ \\
\hline PLANALTINA & $\begin{array}{l}\text { CENTRO } \\
\text { INTEGRADO } \\
\text { DE } \\
\text { EDUCAÇÃO } \\
\text { MODELO } \\
\text { CIEM }\end{array}$ & $\begin{array}{l}\mathrm{R} \$ \\
24.060,00\end{array}$ & & $\begin{array}{l}\mathrm{R} \$ \\
4.776,00\end{array}$ & $\begin{array}{l}\mathrm{R} \$ \\
28.836,00\end{array}$ \\
\hline PLANALTINA & $\begin{array}{l}\text { COLÉGIO } \\
\text { ESTADUAL } \\
\text { COMPLEXO } 3\end{array}$ & $\begin{array}{l}\mathrm{R} \$ \\
12.020,00\end{array}$ & & $\begin{array}{l}\mathrm{R} \$ \\
8.472,00\end{array}$ & $\begin{array}{l}\mathrm{R} \$ \\
20.492,00\end{array}$ \\
\hline PLANALTINA & $\begin{array}{l}\text { COLÉGIO } \\
\text { ESTADUAL } \\
\text { COMPLEXO } \\
\mathrm{N}^{\circ} 10\end{array}$ & $\begin{array}{l}\mathrm{R} \$ \\
11.460,00\end{array}$ & & $\begin{array}{l}\mathrm{R} \$ \\
12.420,00\end{array}$ & $\begin{array}{l}\mathrm{R} \$ \\
23.880,00\end{array}$ \\
\hline PLANALTINA & $\begin{array}{l}\text { COLÉGIO } \\
\text { ESTADUAL } \\
\text { COMPLEXO } \\
07\end{array}$ & $\begin{array}{l}\mathrm{R} \$ \\
22.280,00\end{array}$ & $\begin{array}{l}\mathrm{R} \$ \\
24.000,00\end{array}$ & $\begin{array}{l}\mathrm{R} \$ \\
12.420,00\end{array}$ & $\begin{array}{l}\mathrm{R} \$ \\
58.700,00\end{array}$ \\
\hline $\begin{array}{l}\text { SANTO } \\
\text { ANTÔNIO DO } \\
\text { DESCOBERTO }\end{array}$ & $\begin{array}{l}\text { CAIC JOSÉ } \\
\text { ELIAS DE } \\
\text { AZEVEDO }\end{array}$ & $\begin{array}{l}\mathrm{R} \$ \\
26.960,00\end{array}$ & & & $\begin{array}{l}\mathrm{R} \$ \\
26.960,00\end{array}$ \\
\hline $\begin{array}{l}\text { SÃO JOÃO } \\
\text { DALIANÇA }\end{array}$ & $\begin{array}{l}\text { COLÉGIO } \\
\text { ESTADUAL } \\
\text { PEDRO } \\
\text { LUDOVICO } \\
\text { TEIXEIRA }\end{array}$ & $\begin{array}{l}\mathrm{R} \$ \\
10.980,00\end{array}$ & & $\begin{array}{l}\mathrm{R} \$ \\
8.472,00\end{array}$ & $\begin{array}{l}\mathrm{R} \$ \\
19.452,00\end{array}$ \\
\hline
\end{tabular}


Tabela 04 - Relação das Unidades Executoras do PDDE da macrorregião VIII, em 2016. Valores nominais $(\mathrm{R} \$)$.

\begin{tabular}{ccccc|c}
\hline TOTAL & $\mathbf{R} \$$ & $\mathbf{R} \$$ & $\mathbf{R}$ & $\mathbf{R} \$$ & $\mathbf{R} \$$ \\
& $\mathbf{2 1 9 . 8 0 0 , 0 0}$ & $\mathbf{R}-$ & $\mathbf{2 4 . 0 0 0 , 0 0}$ & $\mathbf{4 6 . 5 6 0 , 0 0}$ & $\mathbf{2 9 0 . 3 6 0 , 0 0}$ \\
\hline
\end{tabular}

Fonte: Brasil, 2016. Tabela elaborada pelos autores.

Com relação à valorização docente através do salário dos profissionais contratados via CLT pela OSE, fica evidente que sua remuneração não terá como base a Lei $\mathrm{n}$. 11.738/2008, pois, segundo o Chamamento Público n. 001/2017:

Considerando que um dos pressupostos da gestão compartilhada é que os
contratos temporários serão substituídos por funcionários regidos pela CLT, as
estimativas de gastos com pessoal devem ser revistas levando-se em
consideração a revisão do piso nacional prevista em 7,64\% e a estimativa de que
os salários dos professores regidos pela CLT deverão ficar em patamares
próximos aos do piso nacional, bem como os encargos decorrentes desse
regime, os quais não incidem sobre os contratos temporários. (GOIÁS, 2017a, p.
83, grifo nosso).

O chamamento afirma que o salário dos funcionários deverá ficar em patamares próximos ao piso nacional, o que abre uma brecha para que a OSE não cumpra a lei e mantenha os salários abaixo do Piso Salarial Profissional Nacional (PSPN). Contudo, cabe ressaltar que, na Planilha de Estimativas de Custo, o governo previu o reajuste de 7,64\% para os profissionais do magistério conforme estabelecido pela Lei n. 11.738/2008. Na Minuta de Contrato de Gestão, está previsto que a OSE terá que garantir o pagamento do piso salarial dos empregados celetistas, qualquer que seja a categoria profissional, mas, por se tratar de uma minuta, essa norma pode não estar presente no Contrato de Gestão e mesmo que permaneça poderá não ser cumprida caso não haja repasse da Seduce para que a OSE atenda essa norma.

O governo afirma que a contratação de funcionários pelo regime de CLT será melhor, pois assegurará direitos que não vislumbram como contratados. Embora isso seja coerente, há que se ressaltar que o contrato temporário tem como objetivo suprir uma vacância de um servidor por um dado período. Sendo assim se uma professora está grávida é correto legalmente que se contrate uma professora para substituí-la enquanto durar a vacância, há de se convir que não teria sentido abrir a vaga da professora grávida em um concurso público, pois a vacância é temporária.

Já o contrato via CLT permite que o funcionário fique por tempo indeterminado no serviço público, podendo até se aposentar, o que pode ser extremamente lesivo ao serviço público, pois, além de retardar ou impossibilitar os concursos públicos, o empregado público via CLT poderá não se filiar a sindicatos de classe ou nem mesmo aderir à greve por melhores condições de trabalho, haja vista que o governo poderá demiti-lo, o que dificilmente ocorre com servidores concursados. O receio ou mesmo medo de perder seu 
emprego poderá ser maior que a vontade de lutar por melhores condições de trabalho, levando em consideração que o aviltamento e a precarização dos profissionais da educação são realidades na rede estadual.

Outro ponto importante se refere aos recursos do Fundeb e do FNDE/MEC, pois o Chamamento n. 001/2017 prevê que não sejam repassados para a OSE; no entanto, conforme a Tabela II é possível constatar que o governo reservou no orçamento volumosos recursos do Fundeb e do FNDE/MEC para a gestão compartilhada. Infere-se com isso que o chamamento se preocupou em atender uma determinação da justiça, mas, contraditoriamente, não o fez no seu orçamento para 2017. E, caso o governo, de fato, não repasse recursos do Fundeb e do FNDE/MEC, é discutível a função da OSE para gerenciar as unidades escolares, pois nem autonomia financeira terá para movimentar a maior parte dos recursos financeiros reservados para a gestão compartilhada, pois, segundo o chamamento, quem gerenciará os recursos do Fundeb e do FNDE/MEC será a própria Seduce.

Com relação às planilhas de estimativas de custos com a gestão compartilhada do Chamamento Púbico n. 001/2017, é possível constatar que são pouco claras ou até mesmo omissas no tocante às informações importantes, como a fonte de recursos para custear as despesas previstas. Outro aspecto já mencionado é o não repasse de recursos do Fundeb e do FNDE/MEC para a OSE, pois não fica claro como serão custeadas as despesas de pessoal, haja vista que esses recursos correspondem a uma parte significativa dos custos com a gestão compartilhada. Além disso, no Modelo de Planilha de Custos/Despesas Mensais, que deve ser preenchida pela OSE, está prevista a receita com os recursos do FNDE/MEC, o que é contraditório com o que afirma o próprio chamamento ao determinar que não haverá repasses dessa fonte orçamentária para a OSE.

A gestão compartilhada não enfrenta um dos maiores problemas acerca do financiamento da educação pública que é o custo aluno. A base para o cálculo do custo aluno utilizada pela Seduce foi o conjunto de despesas das unidades escolares com água, energia, manutenção, merenda e pessoal. Estas despesas foram corrigidas Índice Nacional de Preços ao Consumidor Amplo (IPCA), depois somadas e divididas pelo número de alunos que serão atendidos pela gestão compartilhada. A média ponderada foi considerada pela Seduce como a mais adequada para ser o valor do custo aluno para a implantação da gestão.

O custo aluno, segundo a Lei n. 13.005 de 2014, deveria refletir as necessidades de um padrão de escola de qualidade, e com certeza, não poderia ser implantado em apenas algumas escolas, mas sim, em toda a rede estadual. Neste sentido percebe-se que o governo goiano não tem buscado resolver entraves profundos, no que se refere, à melhoria da qualidade na sua rede de ensino, mas, tão somente, apresentar projetos para algumas 
unidades escolares fomentando assim uma rede paralela de ensino, provavelmente, para que tais escolas sirvam de modelo e sejam alvo das avaliações de larga escala.

Cabe destacar que a gestão compartilhada só atenderá a alunos do ensino fundamental anos finais parcial urbano, do ensino médio parcial urbano e da Educação de Jovens e Adultos (EJA) 2. ${ }^{a}$ e 3. ${ }^{a}$ etapas. A Seduce previu para os Chamamentos Públicos $n$. 003/2016 e n. 001/2017 o custo de $\mathrm{R} \$ 351,11$ e $\mathrm{R} \$ 352,33$, respectivamente, por aluno ao mês. Obviamente, há diferença de custos entre alunos do Ensino Fundamental anos finais, do Ensino Médio e da EJA, e essa diferença deveria ser levada em consideração ao estimar os gastos com os alunos.

Ao analisar as Minutas de Contrato de Gestão dos Chamamentos Públicos n. 003/2016 e n. 001/2017, no que se refere aos recursos financeiros, é possível constatar que há possibilidade de a OSE complementar seus recursos através de: doações, legados, patrocínios, apoios e contribuições de entidades nacionais ou estrangeiras, públicas ou privadas; rendimentos de aplicações de ativos financeiros e outros ingressos, devidamente comunicados ao governo.

Ao permitir que a OSE receba recursos de doações, legados, patrocínios, apoios e contribuições, sem definir claramente regras, o governo permite que haja a possibilidade de que esses recursos não sejam aplicados na atividade-fim do contrato de gestão. Tais recursos, por não serem, a princípio, passíveis de tributação, estão fora do controle administrativo-fiscal peculiar às demais atividades econômicas. Aliás, a minuta sequer afirma que deverão ser utilizados na atividade-fim do contrato de gestão. Esse item da minuta poderá facilmente servir como uma porta para a corrupção ou a lavagem de dinheiro por parte da OSE.

Com relação aos rendimentos de aplicações de ativos financeiros, é importante ressaltar que a LDB no seu art. $69, \S 4 .^{\circ}$ determina que, a cada três meses do exercício financeiro, a diferença entre a receita e a despesa previstas e as efetivamente realizadas que não atenderem ao percentual de 28,25\% (percentual previsto na Constituição do Estado de Goiás para a MDE) deve ser apurada e corrigida para que não haja prejuízo para a educação estadual. Prática recorrente é que os governos não apliquem o percentual mínimo durante o exercício financeiro e, ao final, desesperadamente, apliquem o montante que deixaram de aplicar durante os meses, investindo, assim, de maneira não planejada, na MDE, ou então, que apenas empenhe a despesa para alcançar esse percentual e cancele no exercício seguinte.

O rendimento financeiro dos recursos do Fundeb, em 2016, foi de $\mathrm{R} \$ 5,2$ milhões, ou seja, significativo; ainda é bom lembrar que essa receita não deve ser contabilizada dentro do percentual mínimo vinculado à MDE e, sim, na educação. O governo de Goiás omitiu a receita de rendimento financeiro de impostos em vários exercícios financeiros, como afirma Davies (2010, p. 445): 
Outra omissão em todos os anos (1991 a 1998 e 2006 a 2008) foi o rendimento financeiro auferido com os $30 \%$ dos impostos (ou com os $28 \%$ fixados pela Emenda Constitucional $n^{\circ} 33$, de janeiro de 2003, e com as outras receitas vinculadas integralmente ao ensino (salário-educação, convênios etc.), lançado na rubrica receita patrimonial e, portanto, não incluído nas receitas percentual (relativo ao percentual mínimo dos impostos) ou integralmente vinculadas à MDE.

A questão que se coloca é como o controle dos rendimentos financeiros (contabilização e correção) será realizado no modelo da gestão compartilhada, uma vez que nem mesmo o governo tinha/tem a responsabilidade em realizá-lo? O que poderá ocorrer é a perda dessas receitas agora para o setor privado, ou seja, a OSE.

O Chamamento Público n. 001/2017 permite, ainda, que a OSE complemente seus recursos através da venda de espaço publicitário e exploração comercial das instalações. A venda de espaço publicitário é algo controverso, pois, embora possa representar uma receita a mais para a unidade escolar, a ausência de regras para essa atividade pode prejudicar as escolas e tornar o ambiente agressivo e poluído visualmente.

Dependendo da publicidade, pode haver o estímulo ao consumismo, além disso, a venda de espaço publicitário nas escolas vai de encontro ao Projeto de Lei n. 2640/2015 que tramita no Congresso que pretende alterar o art. 22 da LDB, proibindo que qualquer estabelecimento de ensino da educação básica, público ou privado, de veicular nas suas dependências qualquer atividade de comunicação comercial, inclusive publicidade, para a divulgação de produtos, serviços, marcas ou empresas, independentemente do suporte, da mídia ou do meio utilizado.

A exploração comercial das unidades escolares também é uma questão controversa, pois, ao mesmo tempo em que pode gerar receita para a escola, pode ferir princípios da administração pública, caso a Seduce não defina um processo de seleção ou licitatório que vá ao encontro dos preceitos da administração pública, conforme defendem Neves e Lima (2007, p. 49):

\footnotetext{
Na maioria dos casos a cessão de uso é o título mais apropriado à ocupação por terceiros dos espaços físicos dos órgãos públicos, devendo o gestor, de todo modo, à vista da situação concreta, escolher a forma de utilização rimada com a legislação pertinente ao uso especial de bem público, bem como se calcar na melhor doutrina sobre a matéria.

A observância dos procedimentos licitatórios é como regra necessária, ressalvada a hipótese de inviabilidade de competição, tal como nas situações que envolvem as instituições financeiras oficiais.
}

A Minuta de Contrato de Gestão é omissa no que se refere ao processo de seleção das empresas para divulgação publicitária e exploração comercial. Sendo assim, a OSE poderá escolher as empresas que prestarão esses serviços nas unidades escolares que estiverem gerenciando. Essa escolha poderá passar por algum crivo técnico ou apenas pela vontade pessoal dos dirigentes da OSE, o que de fato é um ataque à administração pública. 
Outro ponto polêmico da Minuta do Contrato de Gestão do Chamamento n. 003/2016, suprimida do Chamamento n. 001/2017, tratava da criação de um fundo de provisionamento constituído de $3 \%$ do valor mensal do repasse, ou seja, o que corresponderia a mais de $\mathrm{R} \$ 2$ milhões, conforme valor estipulado pela própria chamada pública. $\mathrm{O}$ valor do fundo aumentaria, pois seria aplicado no mercado financeiro. A questão é que a minuta não deixou claro o motivo da criação do fundo e quais despesas poderiam ser pagas com os recursos.

Com relação ao teto remuneratório, a título de proventos de qualquer natureza, a ser percebido pelos membros da diretoria da OSE, o Chamamento n. 003/2016 previa o valor do subsídio da Secretária de Estado de Educação, Cultura e Esporte; já o Chamamento 001/2017 prevê o teto do chefe do Poder Executivo estadual. Sendo assim, os membros da diretoria poderão receber um valor bem acima do que estava previsto na chamada anterior, ou seja, a mesma remuneração do governador do estado.

Um aspecto positivo contido nos Chamamentos Públicos n. 003/2016 e n. 001/2017 diz respeito a não cobrança de taxas ou quaisquer contribuições aos alunos das unidades escolares gerenciadas pela OSE. Isso é importante, pois é uma prática que, embora contrarie a CF/1988, tem sido utilizada pelos Colégios Militares. Além da mensalidade de $\mathrm{R} \$ 50,00$, os referidos colégios cobram taxa de matrícula $\mathrm{R} \$ 100,00$ (através de boleto bancário) e a compra de um uniforme específico (farda) que custa, em média, R \$ 500,00.

Sob o ponto de vista pedagógico a gestão compartilhada privilegia o aumento dos índices das avaliações externas como forma de estabelecer metas a serem alcançadas pela OSE. Para Freitas (2004, p. 149) o conceito de avaliação que emergiu, sobretudo, na década de 1990 baseou-se "[...] sob a lógica da competitividade entre as organizações ou entre os professores, em que a qualidade era produto da própria competição e não uma construção coletiva, a partir de indicadores legitimados socialmente pelos atores." Neste sentido a gestão compartilhada fortalece a visão estreita de avaliação ao basear-se nas avaliações externas como indicadores de qualidade da educação endossando princípios do Novo Gerencialismo na educação pública brasileira.

Embora haja muitas incertezas e resistência de movimentos sociais e instituições no processo de implantação e implementação de OS na educação básica, há iniciativas que estimulam a gestão compartilhada com o Terceiro Setor, em âmbito nacional, e poderão estimular e incentivar os governos a implantarem esse projeto em suas administrações. No Senado tramita um Projeto de Lei n. 739/2015, de autoria do senador Cristovam Buarque do Partido Popular Socialista (PPS-DF), que facilitará a transferência de recursos públicos, no caso específico do Fundeb, para as Organizações Sociais.

Além disso, o TCU decidiu que os contratos de OSs em áreas como educação, saúde e cultura não entram no cálculo dos limites de gastos da Lei de Responsabilidade Fiscal (LRF). Isso significa que o salário desses trabalhadores, por exemplo, não vai 
interferir no teto de gastos com pessoal, dando mais liberdade aos governos e, de certa maneira, estimulando-os a intensificar esse tipo de parceria.

\section{ASPECTOS CONCLUSIVO}

A pesquisa revela que há muitas incerteza e incoerências no processo de implantação da gestão compartilhada através da OSE na educação básica, especificamente, no que se refere ao seu financiamento. Entre as fragilidades destacam-se: a dificuldade do próprio governo em prestar contas dos recursos da MDE e da educação, os custos dos alunos calculados sem se levar em consideração as especificidades dos níveis e modalidades em que estão inseridos; os valores orçados em desacordo com os valores apresentados nos chamamentos públicos; as contradições na utilização dos recursos do Fundeb e do FNDE/MEC na gestão compartilhada; a omissão em relação aos recursos do PDDE; a ausência de clareza e de regras na utilização recursos de doações, legados, patrocínios, apoios e contribuições, rendimentos de aplicações, venda de espaço publicitário e exploração comercial das instalações.

O título desta pesquisa questiona se a Organização Social poderá ser a nova panaceia para a educação pública estadual de Goiás. Como resposta, tendo como base a pesquisa, chega-se à conclusão de que, além de a gestão compartilhada entre a OSE e a Seduce não ser uma saída viável para os males da educação estadual, ela poderá ser nociva, sobretudo, no que se refere à transferência de recursos para a OSE.

É inegável que a educação brasileira necessita de uma profunda reformulação, sobretudo, no que se refere à melhoria de sua qualidade, contudo isto não pode ser terceirizado, muito menos, ficar a cargo das autoridades políticas e do Terceiro Setor. É necessária uma revolução na educação pública que possibilite uma melhoria significativa para a comunidade escolar. Muitos avanços e possíveis saídas estão sendo apontadas por especialistas, instituições em conjunto com a sociedade e as mesmas não podem ser substituídas por projetos obscuros de governos que pretendem apenas produzir números e índices que sirvam de plataforma para suas próximas eleições.

Medidas como o reestabelecimento do percentual mínimo de $30 \%$ dos impostos e transferências para a MDE; alcançar um padrão de qualidade através de uma nova metodologia estadual de custo aluno; aplicar devidamente os recursos da educação; fortalecer os conselhos de educação, dentre outras, poderiam melhorar a qualidade da educação estadual. Contudo o desafio de melhorar a qualidade da educação estadual deve ser encarado pelo governo com responsabilidade e com a certeza de que terceirizá-lo pode não ser a melhor solução, mesmo que o governo acredite que esse é caminho mais fácil para enfrentá-lo. 


\section{REFERÊNCIAS}

ADRIÃO, T.; PERONI, V. Implicações do Programa Dinheiro Direto na Escola para a gestão da escola pública. Educação \& Sociedade, p. 253-267, 2007.

ALMEIDA, M. P. Reformas neoliberais no Brasil: a privatização nos governos Fernando Collor e Fernando Henrique Cardoso. 2010. Tese (Doutorado em História) - Departamento de História, Instituto de Ciências Humanas e Filosofia, Universidade Federal Fluminense, Rio de Janeiro, 2010.

BRASIL. Fundo Nacional de Desenvolvimento da Educação. PDDEREX - Relação de Unidades Executoras do PDDE - FNDE. Brasília-DF, 2016. Disponível em: <http://www. fnde.gov.br/pls/internet_pdde/internet_fnde.pdderex_1_pc>. Acesso em: 21 de mar. 2016.

BRASIL. Lei n. 9.637, de 15 de maio de 1998. Brasília-DF, 1998. Dispõe sobre a qualificação de entidades como organizações sociais, a criação do Programa Nacional de Publicização, a extinção dos órgãos e entidades que menciona e a absorção de suas atividades por organizações sociais, e dá outras providências. Disponível em: <http://www.planalto.gov.br/ccivil_03/leis/L9637.htm>. Acesso em: 7 mar. 2016.

BRASIL. Supremo Tribunal Federal. Acórdão da Ação Direta de Inconstitucionalidade ADIN 1.923/DF. Brasília-DF, 2015. Disponível em: <http://www.mpsp.mp.br/portal/ page/portal/cao_cidadania/Terceiro_Setor/Jurisprudencia_ACP/Voto_ADI1923LF.pdf>. Acesso em: 7 mar. 2016. Não paginado.

BRESSER-PEREIRA, L. C. A reforma do estado dos anos 90: lógica e mecanismos de controle. Brasília, DF: Ministério da Administração Federal e da Reforma do Estado, 1997.

DAVIES, N. A fiscalização pelos tribunais de contas de Goiás das receita e despesas vinculadas à educação. Revista Inter-Ação, Goiânia, v. 35, n. 2, p. 437-460, jul./dez. 2010 .

FREITAS, L. C. de. A avaliação e as reformas dos anos de 1990: novas formas de exclusão, velhas formas de subordinação. Educação \& Sociedade, v. 25, n. 86, 2004.

GOIÁS (Estado). Secretaria de Estado de Educação e Cultura e Esporte. Aviso de Chamamento Público n. 001/2016. 2016a. 115 p. Disponível em: <http://www. seduc.go.gov.br/servicos/licitacao/>. Acesso em: 7 mar. 2017.

GOIÁS (Estado). Secretaria de Estado de Educação e Cultura e Esporte. Aviso de Chamamento Público n. 001/2017a. Disponível em: <http://www.seduc.go.gov. br/servicos/licitacao/>. Acesso em: 7 mar. 2017.

GOIÁS (Estado). Secretaria de Estado de Educação e Cultura e Esporte. Aviso de Chamamento Público n. 003/2016b. Disponível em: <http://www.seduc.go.gov. br/servicos/licitacao/>. Acesso em: 7 mar. 2017. 
GOIÁS (Estado). Secretaria de Estado de Gestão e Planejamento. LOA - Lei n. 19.225, de 13 de janeiro de 2016c. Orça a receita e fixa e despesa do Estado para o exercício de 2016. Disponível em: <http://www.segplan.go.gov.br/index.php?option=comcontent\&view= article\&id=18206>. Acesso em: 7 mar. 2016.

GOIÁS (Estado). Secretaria de Estado de Gestão e Planejamento. LOA - Lei n. 19.588, de 12 de janeiro de 2017b. Orça a receita e fixa e despesa do Estado para o exercício de 2017. Disponível em: <http://www.segplan.go.gov.br/index.php?option=comcontent\&view= article \&id=20142\&Itemid=677> . Acesso em: 7 mar. 2017.

GOIÁS (Estado). Tribunal de Contas do Estado de Goiás. Relatório e Parecer das Contas do governo estadual de Goiás 2016d. Disponível em: <https://www.tce.go.gov.br/ CategoriaDownload?idCategoria=461>. Acesso em: 23 ago. 2017.

KOSIK, K. Dialética do concreto. 2. ed. Rio de Janeiro: Paz e Terra, 1976.

MARX, K.; ENGELS, F. O capital: critica de economia política. São Paulo: Abril Cultural, 1988. (O processo de produção do capital, v. 1).

MEIRA, J. C. As organizações sociais e as parcerias na administração. Revista Ágora, Vitória, n. 15, p. 90-109, 2012.

MINISTÉRIO PÚBLICO DO ESTADO DE GOIÁS/MP-GO. 2016a. 14 p. Disponível em: <http://www.mpgo.mp.br/portal/arquivos/2016/02/16/17_36_26_430_Recomenda\%C3\%A 7\%C3\%A3o_MPE_MPF_e_MPC_suspens\%C3\%A3o_edital_OSs_nas_escolas.pdf $>$. Acesso em: 17 out. 2017.

MINISTÉRIO PÚBLICO DO ESTADO DE GOIÁS/MP-GO. Estado e Seduce são acionados por irregularidades no edital para contratação de OS na área da educação. 2016b. Disponível em: <http://www.mpgo.mp.br/portal/noticia/estado-e-seduce-saoacionados-por-irregularidades-no-edital-para-contratacao-de-os-na-area-daeducacao\#.WC5t79IrLcu>. Acesso em: 17 nov. 2016.

NEVES, M.; LIMA, D. H. C. Ocupação por terceiros de espaço físico em bens imóveis de órgãos públicos: análise da juridicidade. Revista do TCU, n. 108, p. 44-50, 2007.

NOVA ESCOLA. Exclusivo: quem vai administrar as escolas de Goiás? Disponível em: <http://revistaescola.abril.com.br/politicas-publicas/radiografia-oss-goias-938045.shtml>. Acesso em: 7 mar. 2016. Não paginado.

O POPULAR: Projeto de OS é um amontoado de plágios da internet. Goiás Real, Goiás, 25 jan. 2017. Disponível em: <http://www.goiasreal.com.br/noticia/5304/o-popularprojeto-de-os-e-um-amontoado-de-plagios-da-internet>. Acesso em: 19 fev. 2017.

PINTO, E. G. Organizações sociais e reforma do Estado no Brasil: riscos e desafios nesta forma de institucionalizar a parceria Estado-Sociedade organizada. Concurso de Ensayos del Clad Administración Pública y Ciudadanía, v. 14, 2000. 
SADDI, R. Quem são as 04 OSs classificadas ontem? Medium, 22 set. 2016. Disponível em: <https://medium.com/@ rafaelsaddi/quem-s\%C3\%A3o-as-04-oss-classificadas-ontem95b8c89deb3c\#.6mphl4rav>. Acesso em: 17 out. 2017.

SINDICATO NACIONAL DOS DOCENTES DAS INSTITUIÇÕES DE ENSINO SUPERIOR - ANDES-SN. 2016. Privatização das escolas públicas avança em Goiás. Disponível em: <http://www.andes.org.br/andes/print-ultimas-noticias.andes?id=8388>. Acesso em: 16 nov. 2016.

SOUZA, R.; SILVA, M. Reestruturações na administração pública brasileira e os desdobramentos na educação superior. Linhas Críticas, v. 14, n. 27, p. 263-282, 2008.

SOUZA, F. A.; FLORES, M. M. L. Uma análise sobre a implementação das organizações sociais nas escolas de Goiás: os recursos públicos em questão. Revista Eletrônica de Educação, v. 11, n. 1, p. 217-229, 2017.

Notas

\footnotetext{
${ }^{1}$ Professor Adjunto da Faculdade de Educação da Universidade Federal do Rio de Janeiro, Pós-doutor em educação pela Universidade Federal de Goiás, Doutor em educação pela Universidade de São Paulo, Mestre em educação, cultura e comunicação nas periferias urbanas pela Universidade do Estado do Rio de Janeiro e Pedagogo pela Universidade do Estado do Rio de Janeiro.

${ }^{2}$ Professora Titular do Programa de Pós-Graduação em Educação da Unidade Acadêmica Especial de Educação da Universidade Federal de Catalão, Pós-doutorado em educação pela Universidade Federal de São Carlos, Doutora em educação pela Universidade Metodista de Piracicaba, Mestre em educação pela Universidade Federal de Uberlândia, Pedagoga pela Pontifícia Universidade Católica de Goiás.
}

Submetido em: 21/02/2018

Aprovado em: 13/08/2018

Publicado em: 28/09/2018 